\title{
Managing Organizational Cultural Influences During the Implementation of Competency-Based Training
}

\author{
John-Paul Hatala \\ James C. Gumm \\ Louisiana State University
}

\begin{abstract}
This article examines organizational cultural influences on a human resource development (HRD) practitioner's ability to effectively implement a competency-based training program. A five-phase conceptual model was created based on the process of implementing a competency-based approach to training and examines how differing agendas from individual organizational members and key stakeholders can derail a program. Suggestions are provided on how HRD practitioners can deal with these influences to increase their chances for successful program implementation.
\end{abstract}

Keywords: organizational culture; model; competency-based training; cultural influences

A natural tension exists in all organizations between the needs of the organization, as defined by key stakeholders, and those of the individual organizational member (Stohl \& Cheney, 2001). One of the manifestations of this organizational tension is found in the role of human resource development (HRD) practitioners and researchers (Swanson \& Holton, 2001) who must account for and design remedies to this tension throughout all phases of organizational training programs. Thus, the challenge for HRD practitioners and researchers is twofold: to provide training that meets the operational needs of the organization while ensuring the individual employee receives personalized training for the purpose of performance improvement and self-fulfillment. Overcoming these challenges is critical to the successful implementation of any HRD training intervention.

Research indicates that a competency-based approach to training is an effective and efficient means of accomplishing the above-mentioned goals.

Advances in Developing Human Resources Vol. 8, No. 2 May 2006 I- 18

DOI: 10.1 1 77//1523422305286/54

Copyright 2006 Sage Publications 
significant amount of research in the public sector realm (Parker \& Bradley, 2000), the purpose of this study was to provide a conceptual model that notes the points of influence both within the organizational culture and competing agendas throughout the design and implementation of a competency-based training program.

The above research has provided the foundation for the conceptual model presented in this article. The conceptual model, which will provide a clearer understanding of the effects of cultural influences, offers practical insight on how to recognize and deal with the cultural influences within an organization throughout the various phases of instructional system design of a competencybased training program. The model provides valuable information for key organizational stakeholders including HRD practitioners and organizational leaders.

This study provides a unique insight on training and development and its nexus with intraorganizational and extraorganizational cultural influences and competing agendas that exist in organizations. This is a concept that required further exploration than what is offered in current HRD literature. This article will add to our knowledge by introducing the concept of cultural influences and their impact on the implementation of competency-based training. In addition, HRD practitioners can utilize the model to develop strategies to deal with cultural influences.

\section{Organizational Culture: Foundation}

"Organizational culture is a popular but elusive concept" (Silvester, Anderson, \& Patterson, 1997, p. 1), as well as a complex and divisive academic issue, and one that practitioners still struggle with. Any study, model, or research agenda that purports to describe, use, or devise a mechanism for the incorporation of organizational culture must first establish the boundaries within which the discussion will take place, because even the very nature of organizational culture is still debated (Corley, 2003; Meyerson \& Martin, 1987).

The major perspective of organizational culture, on which this article and the derived model is based, can perhaps be best described as understanding (or "hearing," as will be described later in this article) a culture within a particular organization as an organizational fugue. To explain this viewpoint, organizational culture's contrapuntal points are delineated into four distinct venues.

The first of these venues is philosophical in nature, and the next two reflect the operational and experientially based views of the authors with regard to the place organizational culture has within the accomplishment of an organization's mission. The final venue is descriptive in nature and concerns the various mechanisms or influences by which organizational culture is expressed in an organization.

Philosophically, organizational life and the culture that develops within the organization are viewed as a multifaceted creation that is a compilation of competing agendas and multiple influences (Whetton \& Godfrey, 1998). This creation has the potential to offer organizational members the opportunity to 


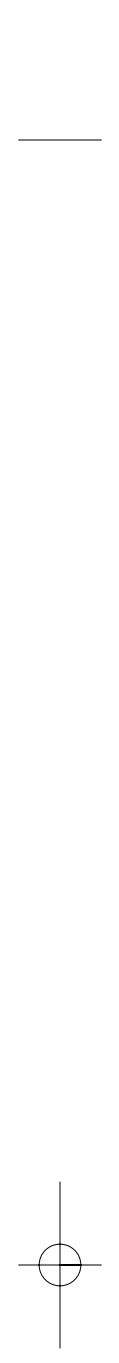

contribute to an endeavor in a unique and meaningful manner (Myerson \& Martin, 1987). As such, the management, development, and attempts to manipulate such powerful institutions must be treated with respect and caution (Gendron, 1997). Incorporated into this philosophical construct is Schein's (1985) view that organizational culture is relatively stable but not monolithic; it can and does change. However, as Schein (1991) also notes, culture is actively resistant to change; it pushes back against anything viewed as a change intervention. This is well represented by Hendry (1999), who stated, "because of its deeply embedded nature any culture, society, institution, or organization, is resistant to change" (p. 563). In fact, this perspective of organizational culture and its intractable nature can be described in an almost biological manner. That is, organizations and their cultures respond or change only when exposed to painful stimuli or problems (Schein, 1991).

In seeming direct conflict with Schein's concept of stability is the authors' and others' view that there is an operational necessity for a modern organization's culture to be a dynamic human endeavor (Kontoghiorghes, Awbre, \& Feurig, 2005) in that the organization must be able to adapt and respond to influences and conditions that change within the marketplace, technology platforms, competitors, and so forth (Tower, 2002). The other operational perspective that helps to explain some of the richness and complexity embedded within this organizational culture as an organizational fugue is the fact that there are individual and collective voices within an organization. These voices are unique and distinct within any organizational culture and can be heard at the individual and subcultural as well as the macroculture level (Martin, 1992). Each must be heard and recognized to fully understand an organization's culture. This is especially crucial for change agents such as HRD professionals, because within each of these voices is the potential for competition, conflict, or cooperation with or against the needs of the organization, other organizational subcultures, or the needs of other individual organizational members (Bluedorn \& Lungreden, 1993).

The final contrapuntal point needed to hear this organizational fugue is how these individual, subcultural, or macro-organization voices express their unique needs and desires. Within the model developed in this study, these expressions are collectively referred to as cultural influences.

These influences are titled individually. Instead of academic definitions, these influences are rather identified by preliminary questions that demonstrate the importance of the influences, the depth of understanding required, and a beginning approach to the methods by which these expressions of voice occur and could be studied by practitioners and scholars:

- Political-what is acceptable organizational politics, who plays, who doesn't;

- Economic - what is financially rewarded, who decides what these rewards are, who controls the distribution, how the equity of the distribution is viewed or explained; 


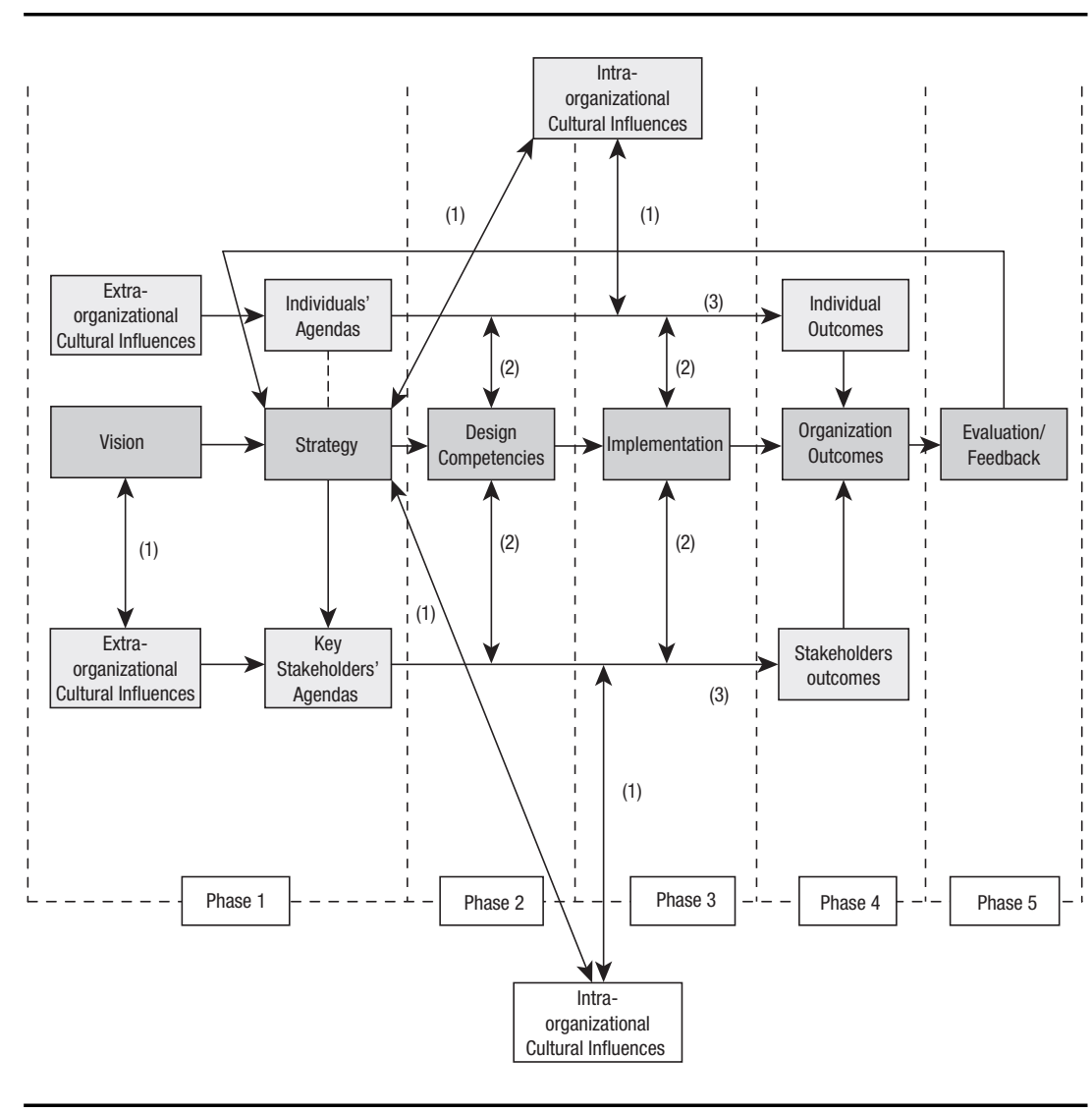

FIGURE I: Conceptual Model-Cultural Influences Model

- Social-who are the influential organizational members; why, how do they become so;

- Communication-how is communication viewed within the organization, how is it used, does this use differ across subculture lines, who talks to whom;

- Leadership -is there an organizational prototype leader, how are leaders developed, chosen.

Each of these are composed of and reflect all three aspects of culture that Schein (1985) refers to as artifacts (rites, rituals, and symbols—visible but not always decipherable); values (testable in ether the physical or social world of the organization - these demonstrate a greater level of awareness of the organization's culture); and basic assumptions (taken for granted, can be invisible or even preconscious). The discernment and complete delineation of the complex 
nature of these influences is needed to fully appreciate the resonance of an organization's culture.

\section{Organizational Culture: Cultural Influences Model (CIM)}

Management of the previously mentioned contradiction between Schein's (1991) view of culture and the need for an organization's culture to be adaptable is the intent of the CIM (see Figure 1).

Change agents, such as HRD professionals involved in the creation, design, implementation, and/or study of a competency-based training program, require a mechanism to deal with an organization's culture. The CIM is proposed as a tool to observe the various interactions with an organization's culture and eventually as a mechanism to assist in the design of effective interventions to assist in the incorporation of a competency-based training program.

For a competency-based program to be effective, there must be a schema shift on the part of the change agent about the organization culture. CIM is based on the following major schema points of organizational culture:

- An organization's culture pushes back against change programs (Lewis, 2000), but it does so in different ways and is represented by different cultural players depending on the current phase of a change project (Foster-Fishman \& Keys, 1997).

- Programs can, will and should be allowed to be affected by an organization's culture; a pure (original) design rarely reflects what is best for the organization (Bullis \& Tompkins, 1989).

- A change agent's major role in this process (separate from the technical aspects of the change program) is the achievement of a program that reflects, as well as possible, the various needs of the organization's members and the strategic goals of the organization (Lewis \& Seibold, 1998).

- Competency-based training is based on the evaluation and identification of an individual's ability to perform within a particular function. This accountability can cause tension between key stakeholders and individual organizational members (Naquin \& Holton, 2003).

\section{Conceptual Model-CIM}

This model addresses the multidimensional nature of the naturally occurring tensions that exist within any organization (Länsisalmi, Peiró, \& Kivimäki, 2000). In particular, this model examines those tensions that affect the design and implementation of a competency-based training program. When considering the design and implementation of competency-based training within either the public or private sector, it is absolutely essential that HRD 
theorists and practitioners recognize, account for, and incorporate the unique cultural makeup of each organization. The uniqueness of an organization's culture has been found to be a key contributor to the success of a modern organization. This contribution is supported by previous research that has demonstrated the existence of a strong relationship between an organization's culture and the development of successful organizational decision-making processes, change adoptions, and innovation efforts, as well as overall organizational performance (Bolman \& Deal, 1997; Kontoghiorghes et al., 2005; Morgan, 1997; Peters, 1992; Stone, 2002; Van Wart, 1998). Wilson (2000) went as far as to claim that the "cultural health of an organization impacts the overall success of the business" (p. 16). Therefore, in order to increase the likelihood of implementing a successful competency-based program, it is imperative that HRD practitioners become aware of the cultural influences that exist.

\section{Processes}

This model is composed of three distinct processes and the impact or influence that each process has on the other. The first of these processes is the fivephase linear model.

The 5-phase model. This model represents the linear progression of a new organizational construct from the creation through to the evaluation of the vision's outcomes. This process is simplified, so that only the competencybased training portion of the process is emphasized. There are numerous other crucial components required for successful vision implementation, but for clarity, only the HRD portion of this process is explained by the model. The distinct phases of this process are seen as:

Phase 1-vision creation and the development of a strategy to accomplish the strategic vision;

Phase 2-design of competencies to support the strategy;

Phase 3-competency implementation (includes the assessment center activity and the development of individualized and group competency-based training program);

Phase 4—operational—or actual organizational work, accomplishment of mission;

Phase 5-feedback/evaluation.

Throughout each phase of this process, two distinct competing value systems mediate the effort to incorporate the new organization vision. The first of these is that of the intraorganizational and extraorganizational influences.

\section{Intraorganizational and Extraorganizational Influences}

As Kurtz (2003) notes, "Past research suggests that organizational culture is a primary and often overlooked key to understanding the organizational 
decision making process" (p. 306). Organizational culture influences all decisions made within organizations; nothing in the concept, construct, design, or implementation of a competency-based program would seem to exclude it from this effect. As demonstrated in the model, these cultural influences are seen as internal organization constructs, that is, the shared values (Schein, 1994), as well as the distinct subculture values that develop in all organizations (Martin, 1992). In addition to the intraorganizational cultural forces that influence the development and implementation of an organization's vision (and competency-based training program), there are numerous extraorganizational influences that have their own unique and frequently even more powerful impact on the implementation of these organizational vision points. This viewpoint of an organization being a culture within a macroculture brings two distinct influence points into view. The first is that its organizational members, both managers and workers, develop and live in this macroculture. They arrive in the organization with well-developed opinions, biases, and world schemas. Each of these is a crucial developmental aspect of an organization's culture. Once established, these world schemas become self-perpetuating through hiring practices (hire and promote those like us) and the development of competencies that reinforce what is important in the organization. Second, the external environment supplies the cues by which threats and opportunities to the organization are identified. These threats and opportunities are filtered through the organizational culture and become the vision points for future development. Once these vision points are identified, then the competencies required to accomplish them can be developed.

\section{Potentially Conflicting Key Stakeholders and Individual Agendas}

The premise that there is a basic conflict between the agendas of management and labor is not new. Fayol (1949), Marx (/1996), Taylor (1911/1967), Weber (1921/1978), and many other management researchers have noted this conflict. What is explicated in the model is the nature of these conflicts and the points of influence toward or restricting the accomplishment of these vision points. It is through these agendas that the success of an implementation plan can be jeopardized if not anticipated. The model depicts a dotted line leading from strategy in Phase 1 to the individual members' agenda. Depending on the involvement of individual members, their agenda may or may not consider the organizational strategy as part of their plan moving forward. This is something that should be considered when deciding who will be involved in the strategy design.

The impact or influences of each of these three processes is the other point of interest described by this model. Each of these influence points will be briefly described. Keep in mind that none of the discussion points here are considered exhaustive but rather should be viewed as starting points for use by 
HRD practitioners in examination of how each of these influences connect within their own organization.

Influences

Extraorganizational influences. Extraorganizational cultural influences are viewed in this model as a bi-directional process when these influences are interacting with the vision or strategy phase of organizational development. One direction of this influence is seen as the stimuli supplied by the extraorganizational influences, for instance, changes that occur in the material supply market. These would have an obvious and potentially large impact on the creation of organizational vision points. But these influences can be and are often countered, supplemented, or supplanted by the decisions or vision points made by senior management, who, through their vision, push back against the extraorganizational influences and force accommodation or change to occur in this arena. This bi-directional effect or influence is easily seen in large organizations. Consider, for instance, the statement, "What is good for General Motors is good for the country," made in 1952 by then CEO Charles Wilson (quoted by Audretsch \& Thurik, 2000). This statement reflected and to this day reflects the power that large organizations have and the influence they can yield. Talking-head analysts often use the phrase, "When Wal-Mart speaks, we listen" to describe a current version of this influence. However, an organization does not require girth and global span to influence its macroculture. Hiring, firing, supply issues, and a myriad of other consequences of an organization's vision have an impact on the macroculture, and thus, are an influence point that must be consider when working in this area.

Extraorganizational influences also enter organizations through the interactions of its key stakeholders and the individual members of this macroculture. This influence is viewed primarily as a one-way influence in that the macroculture influences managers and individual members of the organization (less likely to occur with individuals).

Intraorganizational influences. These influences are what have traditionally been described as the organization's culture; that is, the social and political normative generating processes that have been shown to influence individual member's behaviors (Martin, 1992; Schein, 1991). What this model describes, in addition to these influences, are the mediating effects of these processes on the development of a competency-based program. These influences are shown to occur in the following:

- The development of the strategy to turn the vision of the key stakeholders into an organizational reality. Thus, the effect, conflict, and contribution of what each of the distinct subcultures (i.e., key 
stakeholders and the employees of the organization) view as the who, what, why, and where of the organization (Martin, 1992).

- The progression of both the key stakeholders' and the individual organizational members' agenda to the ultimate outcomes and the changes that occur to those agenda items during this progression. This again reflects the influence of the organizational reality, as seen through the eyes of the participants (Weick, 1979), and the distinct and often conflicting realities of the dominant subcultures (Martin, 1992) within an organization.

Key stakeholders' and individual agendas' influences. These influence points are described in the model as bi-directional; that is, the agenda or the answer to "what's in it for me?" (Gould, 1979), both from the stakeholders' and the individual members' point of view is influenced by the competencies chosen to implement the vision and strategy of upper management. In addition, the desires and needs of these same members influence the final version of these competencies as they are developed and incorporated into the organizational processes.

\section{Application of the CIM for HRD Practitioners}

Up to this point, the discussion has focused on the theoretical implications of organizational cultural influences on the implementation of a competencybased program. The article will turn its attention to the practical applications of the model and how it can help guide HRD practitioners through the implementation process of a competency-based training program. By no means should this be considered a complete list of strategies for working through the model. The purpose of this section is to provide strategies for future competency-based training implementation.

\section{Phase I}

The HRD practitioner may not have any involvement in the development and identification of the organizational vision and strategy. However, they must be aware of not only the vision and the ensuing strategy but a solid understanding of how they came to be. This information will provide valuable insight into the formation of the strategies that guide the organization and, as a result, how it has shaped its culture (Deal \& Kennedy, 2000; Peters \& Waterman, 1982). It is also important to understand the cultural influences that helped form the direction of the organization. Access to this information will help prepare the HRD practitioner for what to expect from individual organizational members in terms of cultural influences. 
TABLE I: Sample Questions to Ask Key Stakeholders

I. Who was involved in the formation of the organizations vision and strategy?

2. How realistic is the vision compared to the present market conditions?

3. How was the organization's strategy developed?

4. Who was involved?

5. Who are the key players involved in carrying out the strategy?

6. How has the vision been marketed to the organizational members?

Assessing the general awareness of the individual organizational member's knowledge of the mission and strategy is important. This can be accomplished by meeting with key stakeholders and discussing the conditions under which the vision and strategy were constructed (see Table 1).

\section{Phase 2}

The second phase involves the development and identification of the competencies. The HRD practitioner may or may not have been involved in this process. If he or she has not been involved, it is imperative to research the history of the development of the competencies to determine how the process was completed. The culture of the organization may have encouraged only select individuals to be involved in the process, which can be perceived by the individual organizational member as a form of alienation. Uncovering this information will provide a frame of reference as to how the competencies will be received by the individual organizational member and allow the HRD practitioner to develop appropriate interventions to address these issues.

If the HRD practitioner is involved in the design of the competencies, steps can be taken to address both the key stakeholders' and the individual organizational members' agendas. One approach is to develop a competency committee, ensuring the members that the committee will continue well after the competencies have been introduced. Competencies should be reviewed on a regular basis to address both intraorganizational and extraorganizational changes. Most important, the members of the committee should represent a large cross-section of the organization. The selection process should involve an objective selection process based on an organization-wide agreement on key individuals. For example, this can be accomplished through a survey asking individuals who they feel can contribute to the competency model development. A typical committee agenda can include the major elements required to build a competency model reflective of the organization (see Table 2).

\section{Phase 3}

The implementation stage is one of the most crucial phases in the entire process. It is important that the HRD practitioner builds into his or her training 


Advances in Developing Human Resources
TABLE 2: Sample Competency Committee Agenda
Agenda
I. What are core competencies and what do we hope to achieve? (a brief description
of what a core competency is and how they will benefit the organizational members)
2. Why identify core competencies?
3. Tying competencies to the organizations vision and strategy
4. How do we put together a list of core competencies?
5. What do we do first? (step-by-step guide including several options and approaches)
6. Sample core competencies
7. How to fill out the core competency forms
May

strategies a review of the previous two phases in order to provide some context to participants. An example of this would be to reiterate the vision and strategy at the beginning of any training session while allowing for feedback from participants. This requires that the HRD practitioner be fully aware of the dynamics of Phases 1 and 2. The competencies designed in Phase 2 should be highlighted in all training materials and delivery (see example in Table 3) to help explain how all training initiatives are linked to competencies.

The implementation process will vary depending on whether competencies existed prior to the training program. If competencies did exist, it can be assumed that the culture of the organization promoted the notion of accountability. However, if the identification of competencies is new to the organization, precautions must be taken to ensure individuals are aware that the accountability of individual performance will come front and center. One of the primary characteristics of competency-based training is that the focus is on the success of each participant, which may be completely contrary to what the participants had previous been exposed to (Watson, 1990).

In addition, a detailed description of the assessment process should be presented to participants to ensure that they are aware of how the competencies were created. Clear definitions and guidelines of how they will be evaluated should be built into the training systems. Assessment centers should be user friendly and involve a mechanism that solicits feedback on the process from participants.

An understanding of the social structure of the organization can be accomplished through network analysis to determine how information flows within the organization (Cross \& Parker, 2004). Identifying how information flows within the organization can help the HRD practitioner anticipate any negative feelings toward a competency-based training program. If opinion leaders are identified, they can be used in the development of the training program to ensure buy-in. Once this occurs, it is hoped that they will spread a positive word to coworkers to increase the likelihood of their having open minds to fully participating in the training program. The HRD practitioner is already 
TABLE 3: Example: Incorporating Competencies Into Training Material and Delivery

Objectives of module

The objective of this module is to assist Service Representatives in providing an excellent customer service experience for every customer.

Coverage will highlight the importance of the right attitude, recognizing moments of truth, and the application of the concept of respect. This section includes material and content familiar to many-however, few will argue against the need to "keep your tools sharp."

Competencies to be covered

\#3 Effectively communicates to customers and associates

\#5 Knowledgeable approach to customer and interaction with others

\#6 Applies personal values to workplace

Skills and Abilities

Listens carefully

Identifies expectations

Is assertive

Willingness to learn

Informs others

Is patient

Provides a service to others

Respectful

Empathetic

aware of the key stakeholders' agenda (Phases 1 and 2) and now should focus on determining what the individual organizational members' agenda consists of. Examples of modules that can help uncover individual agendas include (a) self-awareness programs, (b) career development, (c) goal setting, and (d) development plan design.

A preintervention and postintervention competency profile should be developed to determine improvement once training has been delivered. Any gaps in competencies identified in the preintervention profile should be built into the intervention. Once the intervention has been administered, a postintervention profile can be conducted to determine if an increase in competency level has been obtained.

\section{Phase 4}

Managing the outcomes of the program is as important as every other phase in the implementation process. Two components of this phase that require close monitoring are individual outcomes and key stakeholder outcomes. Individual outcomes pertain to performance indicators identified through a preintervention and postintervention competency profile. The preintervention profile highlights an individual's strengths and weaknesses as they relate to specific competencies. Based on the preintervention assessment and the postintervention results, the HRD practitioner can determine if the intervention has had any impact on improving competency levels. The way in which 


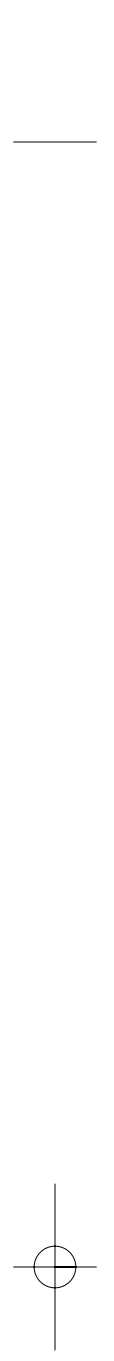

TABLE 4: Balancing Individual Members' And Stakeholders' Outcomes

\begin{tabular}{lccc}
\hline Example & Objectives Score & Multiply Weighting & Total Score \\
\hline Average rating on objectives & 3 & 0.50 & 1.5 \\
Average rating on competencies & 2 & 0.50 & 1 \\
Sum of above two ratings & & & 2.5 \\
\hline
\end{tabular}

competencies are measured varies by organization and should be carefully considered prior to the intervention (Dewey, 1997).

The stakeholders' outcomes can typically be measured through quantitative objectives. For example, reducing the number of employee sick days can easily be monitored and linked to managerial competencies. The key here is to build objective metrics that are easily measured and allow the stakeholders to identify improvements to the business process. However, caution should be taken when measuring outcomes, as they can be difficult to gauge at times due to outside intervention effects that may be beyond the control of the HRD practitioner (Dewey, 1997). Setting expectations and ensuring that the quantitative objectives are realistic and are in keeping with the intervention's intention is important to demonstrating the impact of the program. Overall, finding a balance between the two outcomes is crucial to the program's success and continued support by both the individuals and the stakeholders. Table 4 provides an example of balancing the two outcome scores.

\section{Phase 5}

This phase requires that both the individual organizational members and key stakeholders are continually evaluated to determine the effectiveness of the competency-based program. The evaluation process should examine each phase of the process to determine potential failures that may have occurred throughout the implementation. For example, what is being delivered in a training session (Phase 3) may not be in line with the organization's strategy (Phase 1). Furthermore, if the individual members are aware of this disconnect, training will not be successful, as organizational members will view it as irrelevant and not participate. Evaluating each component of the various phases is an ongoing process and can be accomplished through individual committees with representatives from both the key stakeholders and individual members as an example. As well, as the organization grows and adapts, new cultural influences may arise, changing the agendas on both sides. If this were to occur, a realignment of the competency-based program must be made in order to accommodate these changes.

Feedback to the competency-based program is critical to its success. Not only does the HRD practitioner require feedback on the specific interventions but also the participant's perception of how the organization is implementing 
TABLE 5: Sample Feedback Survey Questions

I. Do you find that the competency-based interventions are in line with the direction of the organization?

2. Are the competency interventions helping you to personally develop within the organization?

3. How are the competency-based interventions helping you with meeting your required objectives?

4. Do you feel that the program is in line with the vision of the organization?

5. How accurately do the competencies reflect what you do?

6. Do the required outcomes match the organization's strategy?

the strategy. A feedback loop should be incorporated into the program to ensure that all sides are providing input on the effectiveness of the interventions. Feedback mechanisms (see sample survey questions in Table 5) should be incorporated into the program to ensure that identified agendas are not altered due to the lack of alignment with the program and the overall organizational goal.

\section{Future Research}

This article has made an attempt to address the process of implementing a competency-based training program by examining cultural influences and their impact on successful delivery. As a result, the CIM was introduced, which helps to explain the implementation process of a competency-based training program and strategies for dealing with these forces. However, further work is required to validate this model. First, greater detail and investigation into the identification and classification of the types of influences within an organization is required. Perhaps quantitative measurement tools can be devised to measure not only cultural influences but the degree of impact each one has on the implementation process.

Second, the identification of the cultural influences at various stages of the process can be isolated to determine the greatest impact based on an organizational profile. The cultural influences identified in this article require further exploration and elaboration as to their overall effect on the implementation process. For example, the political influence can be explored in greater detail to determine how politics affect the implementation process.

Third, multilevel organizational interviews can be conducted to determine the impact cultural influences have on the implementation of a competency-based training program. This can take the form of a case study that addresses the implementation process and the impact culture has had on each phase. 


\section{Conclusion}

The model presented in this article represents an opportunity for HRD practitioners to become aware of the underlying factors to successfully implementing a competency-based training program. More specifically, managing the agendas of both the key stakeholders and individual organizational members will enable the delivery of programs that lead to the desired outcomes. In addition, understanding the nature of organizational cultural influences will allow HRD to design and implement competency-based training that is embraced by the entire organization.

\section{References}

Audretsch, D. B., \& Thurik, A.R. (2000). Capitalism and democracy in the 21 st century: From the managed to the entrepreneurial economy. Journal of Evolutionary Economics, 10(1-2), 17-34.

Bluedorn, A., \& Lungreden E. F. (1993). A culture-match perspective for strategic change. Research in Organizational Change and Development, 7, 137-149.

Bolman, L., \& Deal, T. (1997). Reframing organizations: Artistry, choice, and leadership. San Francisco: Jossey-Bass.

Bullis, C. A., \& Tompkins, P. K. (1989). The forest ranger revisited: A study of control practices and identification. Communication Monographs, 56, 287-306.

Corcoran, T. B. (1976). Prospects and problems of competency-based education. Toledo, OH: The Center for the Study of Higher Education. (ERIC Document Reproduction Service No. ED127874)

Corley, K. (2003). Semantic learning as change enabler: Relating organizational identity and organizational learning. In M. Easterby-Smith \& M. Lyles (Eds.), The Blackwell handbook of organizational learning and knowledge management (pp. 621-636). Oxford, UK: Basil Blackwell.

Cross, R., \& Parker, A. (2004). The hidden power of social networks: Understanding how work really gets done in organizations. Boston: Harvard Business School Press.

Deal, T. E., \& Kennedy, A. A. (2000). Corporate cultures: The rites and rituals of corporate life. Cambridge, MA: Perseus.

Dewey, B. (1997). Six companies share their insights: The challenges in applying competencies. Compensation and Benefits Review, 29, 2.

Fayol, H. (1949). Administration industrielle et générale [General and industrial management] (C. Storrs, Trans.). London: Pitman.

Foster-Fishman, P. G., \& Keys, C. B. (1997). The person/environment dynamics of employee empowerment: An organizational culture analysis. American Journal of Community Psychology, 25(3), 345-369.

Gendron, B. (1997). Technology and the human condition. New York: St. Martins.

Gould, S. (1979). An equity exchange model of organizational involvement. Academy of Management Review, 4(1), 53-62.

Harrow, J., \& Wilcox, L. (1990). Public services management: Attitudes, initiatives, and limits to learning. Journal of Management Studies, 27, 281-303.

Hendry, J. (1999). Cultural theory and contemporary management organization. Human Relations, 52, 557-577. 
Kontoghiorghes, C., Awbre, S. M., \& Feurig, P. L. (2005). Examining the relationship between learning characteristics and change adaptation, innovation, and organizational performance. Human Resource Development Quarterly, 16(2), 183-211.

Kurtz, R. S. (2003). Organizational culture, decision making, and integrity in the National Park Service and the Exxon Valdez. Public Integrity, 5, 305-317.

Länsisalmi, H., Peiró, J. M., \& Kivimäki, M. (2000). Collective stress and coping in the context of organizational culture. European Journal of Work and Organizational Psychology, 9(4), 527-559.

Lewis, L. K. (2000). "Blindsided by that one" and "I saw that one coming": The relative anticipation and occurrence of communication problems and other problems in implementers' hindsight. Journal of Applied Communication Research, 28, 44-67.

Lewis, L. K., \& Seibold, D. R. (1998). Re-conceptualizing organizational change implementation as a communication problem: A review of literature and research agenda. Communication Yearbook, 21, 93-151.

Martin, J. (1992). Cultures in organizations: Three perspectives. New York: Oxford University Press.

Marx, K. (1996). Capital: A critique of political economy (with F. Engels). Lanham, MD: National Book Network. (Original work published PLS. PROVIDE)

Meyerson, D., \& Martin, J. (1987). Cultural change: An integration of three difference views. Journal of Management Studies, 24, 623-647.

Morgan, G. (1997). Images of organization. Thousand Oaks, CA: Sage.

Naquin, S. S., \& Holton E. F., III. (2002). The development of a competency model and assessment instrument for public sector leadership and management development. In T. M. Egan \& S. A. Lynham (Eds.), Refereed Proceedings of the Academy of Human Resource Development Annual Conference. Bowling Green, OH: Academy of Human Resource Development.

Naquin, S. S., \& Holton, E. F., III. (2003). Redefining state government leadership and management development: A process for competency-based development. Public Personnel Management, 32, 23-46.

Parker, R., \& Bradley, L. (2000). Organizational culture in the public sector: Evidence from six organizations. The International Journal of Public Sector Management, 13, 125-141.

Perry, J., \& Rainey, H. (1988). The public-private sector distinction in organization theory: A critique and research agenda. Academy of Management Review, 13, 182-201.

Peters, T. (1992). Liberation management. New York: Fawcett-Columbine.

Peters, T. J., \& Waterman, R. H. (1982). In search of excellence: Lessons from America's best run companies. New York: Harper \& Row.

Scheiber, S., Kramer, T. A., \& Adamowski, S. E. (2003). The implications of core competencies for psychiatric education and practice in the US. Canadian Journal of Psychiatry, 48, 215-221.

Schein, E. (1985). Organizational culture and leadership: A dynamic view. San Francisco: Jossey-Bass.

Schein, E. (1991). The role of the founder in the creation of organizational culture. In P. Frost, L. Moore, \& M. Louis (Eds.), Reframing organizational culture (pp. 14-25). Newbury Park, CA: Sage.

Schein, E. (1994). Organizational and managerial culture as a facilitator or inhibitor of organizational learning. Society for Organizational Learning. Retrieved June 18, 2005, from http://www.solonline.org/res/wp/10004.html. 
Silvester, J., Anderson, N. R., \& Patterson, F. (1997). Organizational culture change: An inter-group attributional analysis. Journal of Occupational and Organizational Psychology, 72(1), 1-23.

Stohl, C., \& Cheney, G. (2001). Participatory practices/paradoxical practices: Communication and the dilemmas of organizational democracy. Management Communication Quarterly, 14, 349-407.

Stone, R. J. (2002). Human resource management (4th ed.). Chichester, UK: Wiley.

Swanson, R. A., \& Holton, E. F., III. (2001). Foundations of human resource development. San Francisco: Berrett-Koehler.

Taylor, F. W. (1967). The principles of scientific management. New York: Harper and Brothers. (Original work published 1911)

Tower, D. (2002). Creating the complex adaptive organization: A primer on complex adaptive systems. OD Practitioner, 34(3). Retrieved from http://www.odnetwork .org/odponline/vol34n3/creating.html

Van Wart, M. (1998). Changing public sector values. New York: Garland.

Watson A. (1990). Competency-based vocational education and self-paced learning. Sydney, Australia: Technology University. (ERIC Document Reproduction Service No. ED324443).

Weber, M. (1978). Economy and society. In G. Roth \& C. Weick (Eds.), The social psychology of organizing (2nd ed., pp. 941-958). Reading, MA: Addison-Wesley. (Original work published 1921)

Whetten, D. A., \& Godfrey, P. C. (Eds.). (1998). Identity in organizations: Developing theory through conversations. Thousand Oaks, CA: Sage.

Wilson, R. (2000). Organizational culture analysis. Strategic Communication Management, 4(6), 16-20.

John-Paul Hatala is an assistant professor in the School of Human Resource Education and Workforce Development, Louisiana State University, Baton Rouge. His academic research has focused on the transition toward re-employment, social capital in the workplace, barriers to entrepreneurship, social networking behavior, and organizational development.

James C. Gumm is an experienced manager who has worked in the private, public, and military sector. His educational background includes degrees in construction and industrial technology, as well as a master's in organizational communication. He is currently on sabbatical from his Ph.D. studies in organizational development while working at the Louisiana Family Assistance Center, assisting in the reunification and identification of victims from Hurricanes Katrina and Rita.

Hatala, J.-P., \& Gumm, J. (2006). Managing organizational cultural influences during the implementation of competency-based training. Advances in Developing Human Resources, 8 , $\mathbf{x x x}-\mathbf{x x x}$. 